\title{
Didatização do gênero anúncio publicitário no livro didático de português do ensino médio: uma abordagem discursiva
}

\author{
The teaching of the gender advertising in high school portuguese textbooks: a \\ discursive approch
}

\author{
José de Alcântara Ribeiro da Silva ${ }^{1}$
}

João de Deus Leite ${ }^{2}$

Recebido em: 30/10/2019

Aprovado em: 08/06/2020

Publicado em: 30/06/2020

\begin{abstract}
RESUMO: Neste artigo, interessa-nos analisar e problematizar o modo como o gênero textual anúncio publicitário é alçado a objeto de abordagem no livro didático de Português do ensino médio. Para tanto, na esteira do que Pêcheux (2014) concebeu como "divisão social do trabalho da leitura", vamos derivar a perspectiva de que, nessa didatização, há processos discursivos que produzem unidade-dispersão na incorporação desse gênero no livro didático. Para procedermos às análises, consideramos o anúncio publicitário na sua relação com os exercícios que a ele estão vinculados no livro. Teórico-analiticamente, para pensar a questão da unidade-dispersão, vamos partir da perspectiva de que a didatização põe em jogo a base material dos processos discursivos: Que tipo de anúncio publicitário é mobilizado? Que tipo de exercício é produzido sobre ele? Não podemos nos esquecer de que a escolarização desse gênero aponta para a referida divisão de sentidos, dadas as condições de produção do livro didático, no âmbito do Programa Nacional do Livro e do Material Didático (PNLD). Além disso, há as discursividades instauradas pelos documentos oficiais sobre o ensino de Língua Portuguesa. As análises mostram que os exercícios fazem acentuar a "divisão social do trabalho da leitura", inserindo o gênero no jogo entre unidade-dispersão.
\end{abstract}

Palavras-chave: Livro Didático; Gênero “Anúncio Publicitário”; Discurso; Escolarização.

ABSTRACT: This article discusses how the textual gender of advertising is approached in High School Portuguese textbooks. For such a purpose, we take what Pêcheux (2014) conceives as a social division of the work of reading in order to assume that in this process of making the gender of advertising as an object of teaching there are unit and dispersion when the textbook incorporates such a gender. The analysis undertaken takes into account the advertising in its relation to the exercises proposed in the textbook. The unit-dispersion is thought from the point of view that considers that the didacticism mobilizes the material basis of the discursive processes, raising up the following questions: what kind of advertising is shown in this context? What kind of exercise is proposed about the gender of advertising? It is necessary to have in mind that the schooling of this gender indicates that meanings are spread out. This is so because of the conditions under which textbooks are produced by the so called National Program of Textbooks and Didactic material (PNLD). In addition, another aspect that influences the way exercises are proposed for the teaching of the advertising are the official documents used to guide the teaching of Portuguese Language. The analysis shows that the exercises increase the "social division" of the work of reading, leading the gender of advertising to the game between unit-dispersion.

Key-words: Textbook; Gender; Advertising; Discourse, Schooling

1.Graduado em Letras pela Universidade Estadual do Maranhão, mestrando na Universidade Federal do Tocantins.ORCID: 0000-0002-2679-326X E-mail: profmaalcantara@hotmail.com 2.Professor e doutor na Universidade Federal do Tocantins.ORCID: 0000-0002-8918-9940 E-mail: joaodedeusleite@hotmail.com 


\section{INTRODUÇÃO}

Neste artigo, analisamos e problematizamos o modo como o gênero textual anúncio publicitário é incorporado ao livro didático de Língua Portuguesa do ensino médio. Para tanto, interessa-nos, mais especificamente, a ocorrência em si desse gênero, na sua relação com os exercícios que estão circunscritos a ele. Essa relação compõe a aula de leitura e de escrita no espaço escolar brasileiro, visto que os livros didáticos são um dos recursos pedagógicos que tem maior alcance. Como ainda abordaremos, neste artigo, o Programa Nacional do Livro e do Material Didático (PNLD), na condição de política pública educacional, assegura a avaliação, a seleção e a distribuição dos livros didáticos. Inscritos na perspectiva da Análise de Discurso francesa, de orientação peuchetiana, estamos concebendo a incorporação desse gênero textual a partir de certas condições de produção. $\mathrm{Na}$ esteira de Pêcheux (2014), podemos destacar que tal apropriação se inscreve no que esse teórico postulou como "divisão social do trabalho da leitura" (PÊCHEUX, 2014, p. 60).

Vamos derivar algumas considerações do texto "Ler o arquivo hoje", de Michel Pêcheux (2014), para cumprirmos os nossos objetivos neste artigo. Ao procedermos a essa derivação, significa dizer que Pêcheux (2014) não enfocou a questão da escrita, como objeto de reflexão, nem a escrita escolar. Essa escrita se configura como uma inquietação nossa. Ele, também, não enfocou a leitura que se trabalha na escola. O foco desse teórico esteve pautado na leitura como uma prática discursiva geral. Buscando inspiração em Pêcheux (2014), proporemos que o modo como são concebidas e trabalhadas a leitura e a escrita, na escola, está integrado a essa divisão social do trabalho da leitura e da escrita. Trata-se de pensar, antes de tudo, que leitura e escrita são atividades que resguardam uma relação. No caso do espaço escolar brasileiro, essa relação tende a se acentuar, até pela necessidade, por exemplo, de articulação dos eixos estruturadores da Língua Portuguesa, como componente curricular.

Na perspectiva proposta por Pêcheux (2014), o arquivo (im)põe aos profissionais da leitura deste uma relação com a materialidade discursiva. Para usarmos seus termos, tratase de "materiais discursivo-textuais". E essa materialidade encerra uma inscrição da língua na história. A essa incursão, Pêcheux (2014) denominou de discursividade. Eis, nas palavras do autor, a definição de discursividade: "[...] a discursividade como inscrição de efeitos linguísticos materiais na história, que constitui o nó central de um trabalho de leitira de arquivo" (PÊCHEUX, 2014, p. 66; grifos do autor).

Revista do SELL, Uberaba/MG (online) - V. 9 n. 1, p. 142-160, jan. /jun. - 2020. 
SILVA,J.A.R.; LEITE,J.D.

Para dizermos do foco deste artigo, o livro didático pode ser considerado como um trabalho sobre o arquivo, pois ele envolve uma relação com outros documentos. Para Pêcheux (2014, p. 59), a leitura do arquivo põe em relação um "campo de documentos pertinentes e disponíveis sobre uma questão". O livro didático, como arquivo, no cenário educacional brasileiro, põe em relação: (1) documentos oficiais norteadores de ensino; (2) edital de chamada para os autores que almejam propor livros didáticos; (3) guia do livro didático, que divulga os livros selecionados para a futura seleção de professores da educação básica.

Constitutivo a esse campo de documentos, há a divisão social do trabalho da leitura e da escrita, quando estas são alçadas a objeto de ensino e de aprendizagem. É que os diferentes tipos e gêneros textuais são selecionados e abordados nos livros didáticos de Língua Portuguesa, com base na política linguística que se inscreve ao ensino e à aprendizagem dessa língua. Essa política linguística opera efeitos no modo como se deve ler e escrever na escola. E os referidos documentos buscam produzir discursividades acerca do modo como a leitura e a escrita devem ser trabalhadas, na tentativa de assegurar um efeito de unidade para o ensino e a aprendizagem de Língua Portuguesa. Há uma tentativa de homogeneização dos gestos de leitura e de escrita nessa divisão do trabalho de leitura. Sob o viés pecheutiano, há o risco "[...] de um policiamento dos enunciados, de uma normalização asséptica da leitura e do pensamento, e de um apagamento seletivo da memória histórica [...]". (PÊCHEUX, 2014, p. 63; grifos do autor).

Reconhecemos a importância das tentativas imaginárias sobre os gestos de leitura e de escrita, no processo de escolarização destas. Contudo, é preciso lançar luz ao processo de dispersão que essa escolarização produz. No caso deste artigo, é necessário analisar e problematizar os processos discursivos que mostram os pontos de unidade e de dispersão da didatização do gênero discursivo anúncio publicitário no livro didático de Português, do ensino médio, conforme já ressaltamos anteriormente.

Por "processo discursivo", estamos compreendendo a base material dos sentidos. Assim, ao ser incorporado ao livro didático do meio de tantas abordagens, produz-se algumas. Contudo, como o sentido é material, as possibilidades apagadas ainda existem e são constitutivas das abordagens formuladas. Por serem constitutivas, é possível que o linguístico e o não linguístico se inscrevam na história. É por esse processo discursivo que a leitura e a escrita se abrem aos pontos de deriva.

Como o livro didático é ferramenta importante no processo de divisão social do trabalho da leitura e da escrita, a seleção e a abordagem dos diferentes tipos e gêneros assentam-se nesse processo discursivo de apagamento de outras possibilidades. Porém, 
SILVA,J.A.R.; LEITE,J.D.

cabe-nos ressaltar que as outras leituras e escritas possíveis são autorizadas por haver essa base material dos sentidos. Neste ponto, estamos considerando o binômio unidadedispersão para pensarmos a seleção e a abordagem dos textos.

No processo de leitura e de escrita, no espaço de sala de aula, os outros sentidos materialmente constituídos veem à tona no gesto de leitura e de escrita empreendido pelo aluno. Esse espaço é fruto de uma dupla relação: (1) das circunstâncias imediatas, denominadas por Orlandi (2014) de "contexto em sentido estrito"; (3) das determinações histórico-ideológicas, que são o "contexto em sentido lato", também na esteira de Orlandi (2014). Essas duas relações apontam para o fato de que o aluno, ao ler e ao escrever, está ancorado nessas circunstâncias e nessas determinações.

Este artigo se mostra relevante, uma vez que estamos tematizando o processo complexo de seleção e de abordagem de um tipo de gênero discursivo específico, no caso o anúncio publicitário. Jogar com a unidade e a dispersão é conceber que toda e qualquer leitura e escrita traz em seu bojo de constituição o efeito do recorte do gênero alvo da incorporação ao livro didático. Como já destacamos anteriormente, vamos partir da concepção de que os livros didáticos compõem a divisão social de trabalho de leitura e de escrita, pondo em circulação, no espaço escolar, certos sentidos, certos modos de leitura e de interpetração. Neles, são alçados diferentes gêneros textuais, engendrando uma projeção imaginária de leitor, por um lado; por outro, há processos discursivos que deixam entrever um modo de se ser autor. Compõem ao lugar discursivo de autor os gestos de apropriação dos diferentes e tipos textuais. Sob a perspectiva discursiva, vamos trabalhar que, ao exercer esse lugar, há a constituição de tomadas de posição ("posição sujeito").

Dessa forma, o anúncio publicitário tem sido mobilizado, cada vez mais, no âmbito dos livros didáticos de Língua Portuguesa, para se fomentar o trabalho com questões de leitura (compreensão e interpretação) e com questões de escrita, tendo os aspectos da língua e da gramática normativa como ponto de aplicação. Por estar inserido no livro didático, esse gênero textual reclama ser considerado não mais em função de sua esfera social de origem, mas, sim, na esfera escolar. Essa esfera abre horizontes para se pensar nos efeitos da didatização desse gênero no livro didático, tendo em vista, inclusive, a política linguística que é construída pelo Programa Nacional do Livro e do Material Didático (PNLD), conforme já fizemos menção. 
SILVA,J.A.R.; LEITE,J.D.

\section{Das condições de produção do livro didático do ensino médio enfocado}

Nesta seção, buscando dimensionar as condições de produção do livro "Português Contemporâneo - diálogo, reflexão e uso", de William Cereja, Carolina Dias Vianna e Chistiane Damien (PNLD/2018-2020), enfocamos o Edital 04/2015, de Convocação para processo de inscrição e avaliação de obras didáticas para o Programa Nacional do Livro Didático PNLD 2018; e o Guia PNLD 2018. Esses dois documentos integram, diretamente, o quê, na esteira de Pêchuex (2014), viemos considerando como "divisão social do trabalho". Sendo assim, no livro didático, não se pode apresentar qualquer tipo de abordagem; há discursividades que concebem alguns modos de se estruturá-lo.

O Edital 04/2015 CGPLI, totalizando setenta e cinco páginas, está estruturado do seguinte modo: (1) Do objeto; (2) Dos Prazos; (3) Das Características das Obras Didáticas; (4) Das Condições de Participação; (5) Da Etapa de Inscrição; (6) Das Etapas de Triagem, Pré-análise e Avaliação Pedagógica das Obras; (7) Da Acessibilidade; (8) Das etapas de Habilitação, Negociação e Contratação; (9) Das Etapas de Produção, Controle de Qualidade e Distribuição; (10) Das Disposições Gerais.

Aparecem, nos anexos, os seguintes documentos: Anexo I - Estrutura Editorial e Critérios de Exclusão na Triagem; Anexo II - Especificações Técnicas para a Produção das obras Didáticas; Anexo III - Princípios e Critérios para a Avaliação de Obras Didáticas; Anexo IV - Modelo de Declaração de Edição; Anexo V - Modelo de Declaração de Originalidade; Anexo VI - Modelo de Declaração de Primeira Avaliação; Anexo VII - Modelo de Declaração de Reinscrição; Anexo VIII - Modelo de Declaração de Revisão e Atualização da Obra; Anexo IX - Modelo de Ficha de Correção da Obra; Anexo X - Modelo de Declaração Emprego Menor; Anexo XI - Relação de Documentos a serem Entregues pelo Editor; Anexo XII - Modelo de Declaração de Titularidade de Direito Patrimonial; Anexo XIII - Modelo de Formulário de Habilitação; Anexo XIV - Modelo de Ficha Cadastral; Anexo XV - Modelo de Declaração de Inexistência de Fato Impeditivo.

Interessa-nos particularizar, neste ponto, um recorte discursivo sobre os critérios específicos que podem eliminar a obra didática a ser apresentada para o componente curricular Língua Portuguesa. Esses critérios aparecem, no Anexo III - Princípios e Critérios para a Avaliação de Obras Didáticas, do edital em questão. Consideremos, a seguir, o recorte:

3.1.1.2. No tratamento didático dado ao ensino e aprendizagem da leitura e da escrita, as propostas devem: a. contemplar significativamente as formas de expressão e os gêneros mais estreitamente associados às culturas juvenis. Para o trabalho com o texto literário, priorizar a leitura das obras dos diferentes gêneros literários (poesia lírica, conto, crônica, literatura

Revista do SELL, Uberaba/MG (online) - V. 9 n. 1, p. 142-160, jan. /jun. - 2020. 
dramática, romance, novela, literatura de cordel, dentre outros), dispostos, quando possível, na íntegra (sobretudo, os poemas líricos) e selecionados segundo os interesses e a faixa etária do leitor; b. explorar sistematicamente gêneros próprios de esferas públicas e os mais frequentes no mundo do trabalho; c. incluir, nas temáticas propostas para a leitura e a produção de textos, as preocupações éticas próprias da condição juvenil, subsidiando os debates com textos opinativos, argumentativos e expositivos; d. propiciar a formação do leitor de literatura, focalizando a leitura literária numa perspectiva intertextual, intersemiótica e interdisciplinar, pela qual os textos literários possam ser compreendidos em suas dimensões estética, histórica e cultural, a partir das relações, observações e reflexões construídas no próprio ato de ler, afastando-se, assim, de um ensino pautado na aplicação de conceitos teóricos prontos e na simples memorização de um grande número de escritores(as) e obras, sem uma vivência efetiva com o texto literário; e. considerar o impacto dos novos suportes e tecnologias de escrita sobre a construção e a reconstrução dos sentidos de um texto; f. abordar efetivamente os modos de ler e de escrever característicos dos textos multimodais e dos hipertextos, promovendo os diferentes letramentos envolvidos em sua leitura e produção (BRASIL, 2018, p.37).

Considerando esse recorte discursivo, podemos destacar alguns trechos, como o fizemos por meio do itálico, a partir dos quais a divisão social do trabalho de leitura e, também, de escrita ganha circunscrição discursiva. É o caso do primeiro destaque, a saber: "[...] contemplar significativamente as formas de expressão e os gêneros mais estreitamente associados às culturas juvenis.", em que se recomenda a abordagem didática de diferentes formas de expressão e de gêneros que sejam familiares às faixas etárias dos alunos da obra didática. Chama-nos a atenção essa recomendação, pois se busca priorizar os gêneros com os quais os alunos, supostamente, poderão se identificar. No edital, o universo discursivo do aluno é denominado de "culturas juvenis".

Ainda por esse recorte, destacamos o seguinte trecho: "[...] explorar sistematicamente gêneros próprios de esferas públicas e os mais frequentes no mundo do trabalho [...]". A ocorrência da palavra "sistematicamente" chamou-nos a atenção. É que um dos critérios a ser analisado é se a abordagem de gêneros textuais é constante na obra didática. Se fizermos uma referência cruzada com as discursividades produzidas, por exemplo, pelos Parâmetros Curriculares Nacionais, de Língua Portuguesa (PCNLP), vamos perceber que se trata da tentativa de se evitar o ensino essencialmente metalinguístico. Daí a importância que os gêneros textuais assumem no ensino de Língua Portuguesa.

Se, por um lado, é recomendada a exploração didática de modo sistemático, por outro, é recomendado, também, que os gêneros sejam de "esferas públicas" e que pertençam ao mundo do trabalho. Assim, incorpora-se a discursividade de que a escola, sobretudo o componente curricular de Língua Portuguesa, precisa colaborar com o aluno no processo de produção e de circulação de diferentes textos na sociedade. Essa discursividade está vinculada à perspectiva de que o aluno é "cidadão"; para tanto, a sua 
SILVA,J.A.R.; LEITE,J.D.

cidadania é assegurada justamente pela participação na produção e na circulação de textos.

Por decorrência, a referida discursividade está relacionada ao viés de que é função da escola, também, organizar os conteúdos, abordando-os em termos de "competência" e de "habilidade", já que o aluno precisa "saber fazer" com os saberes produzidos. O sentido de cidadania em operação, nos documentos oficiais e em diretrizes, é esta em que a centralidade no mundo do trabalho ganha relevância. A serviço de quem se incorpora essa discursividade, inclusive, no livro didático? Neste ponto, podemos salientar que essa incorporação é ancorada na "divisão social do trabalho da leitura" e da escrita.

Também, pautados, nesse recorte discursivo, destacamos mais este trecho: “[...] incluir, nas temáticas propostas para a leitura e a produção de textos, as preocupações éticas próprias da condição juvenil, subsidiando os debates com textos opinativos, argumentativos e expositivos". Nesse trecho, recomenda-se que as temáticas a serem abordadas, didaticamente, sejam características e peculiares do universo discursivo do aluno. Para tanto, esperar-se que diferentes textos sejam mobilizados, fazendo trabalhar os diferentes domínios sociais de interação humana e as capacidades que eles reclamam "opinar", "argumentar" e "expor", para dizermos das capacidades mencionadas neste ponto do edital.

O Guia PNLD 2018 de Língua Portuguesa, com cento e nove páginas, está estruturado desta maneira: (1) Por que ler o Guia?; (2) A Língua Portuguesa no contexto do Ensino Médio; (3) Princípios e Critérios de Avaliação; (4) Coleções Aprovadas; (5) Resenhas; (6) Ficha de Avaliação; (7) Referências. Esse Guia é disponibilizado às escolas, para que os profissionais de cada área procedam à seleção de cada obra didática. Para cada componente curricular, há um Guia específico, conforme podemos notar no site do Ministério da Educação (MEC). Cada seção que compõe o Guia de Língua Portuguesa é concisa e precisa, em termos de informações disponibilizadas.

Consideremos, a seguir, um trecho transcrito da seção "A Língua Portuguesa no contexto do Ensino Médio":

Esse seria, pois, o ponto de chegada do estudante, no que respeita ao ensino de Língua Portuguesa no Ensino Médio: a apropriação da língua escrita e oral, principalmente das esferas sociais não cotidianas (como a literária, a científica, a jornalística, a publicitária, a do trabalho), o que engloba tanto o domínio da produção quanto a leitura e escuta de diversos gêneros que circulam socialmente. Essa perspectiva de formação no Ensino Médio apoia-se no fato de que se apropriar da língua significa valer-se dela para a compreensão de si mesmo e para a compreensão e construção do mundo em que se está inserido, o que corresponde, em última instância, a tornar-se sujeito capaz de exercer sua plena participação social. Essa orientação demanda, portanto, uma prática de ensino engajada às práticas

Revista do SELL, Uberaba/MG (online) - V. 9 n. 1, p. 142-160, jan. /jun. - 2020. 
sociais de uso da língua, de modo que todos os conteúdos de ensinoaprendizagem de Língua Portuguesa não começariam nem terminariam neles mesmos, mas estariam a serviço do uso realizado por um sujeito socialmente constituído (BRASIL, 2018, p. 09).

Com base nesse recorte discursivo, notamos os efeitos da divisão social do trabalho da leitura e da escrita nesse segmento de ensino. Retorna, no Guia PNLD 2018, a discursividade de que o ensino desse componente curricular, para dizermos do foco deste artigo, deve estar embasado em gêneros. No caso, de gêneros diferentes daqueles próprios da esfera cotidiana. Novamente, ocorre a palavra "esfera" própria das teorizações de Bakhtin, dadas as traduções produzidas no Brasil. Tal palavra expressa a ideia de que cada gênero circula e funciona em cada esfera da sociedade. E o ensino precisa se orientar por esse gesto de apropriação/incorporação.

Pautados, ainda, nesse recorte discursivo, podemos destacar a continuidade dos efeitos da discursividade de que o ensino de Língua Portuguesa deve criar condições para que o aluno se desenvolva como cidadão letrado. Ou seja, que ele participe efetivamente das práticas de leitura e de escrita. Chama-nos a atenção a ideia de que, ao final do ensino médio, o aluno precisa ser "capaz de exercer sua plena participação social” (BRASIL, 2017, p. 09). A discursividade de que a escola figura como uma instituição que deve contribuir com a formação cidadã do aluno continua em funcionamento. Chama-nos a atenção a ocorrência da relação de adjetivação encabeçada pelo adjetivo "plena". Acentua-se a perspectiva de que, ao final da escolarização no ensino médio, o aluno precisa estar apto a participar de todas as práticas sociais. Há uma projecção imaginária de aluno, que em algum momento, chegar-se-à completude e à totalidade da construção de competências e habilidades. Faz-se pensar que essa planificação é fruto do somatório de etapas que vão sendo construídas e vencidas.

Da seção "Coleções aprovadas", vejamos, a seguir, um recorte discurso em que se destaca a qualidade das obras didáticas aprovadas para o ensino médio, nesse componente curricular em questão. Cabe ressaltar que foram aprovadas e recomendadas onze coleções didáticas. Eis o recorte discursivo:

O conjunto das obras aprovadas no PNLD 2018 permite observar o quanto o material dedicado ao ensino-aprendizagem da Língua Portuguesa vem sendo aprimorado. O trabalho pedagogicamente cuidadoso, principalmente nos eixos da Leitura, da Literatura e da Produção Textual, permite inferir um avanço no que concerne às concepções de língua que sustentam as abordagens pedagógicas nas coleções. Já é recorrente a preocupação, por exemplo, em vincular as práticas escolares de leitura e escrita às outras práticas de uso social da leitura e da escrita. Também se observa a presença de projetos que constroem contextos mais significativos para a formação de leitores e escritores (BRASIL, 2017, p. 15).

Revista do SELL, Uberaba/MG (online) - V. 9 n. 1, p. 142-160, jan. /jun. - 2020. 
De posse de mais esse recorte do Guia PNLD 2018, percebemos a ênfase discursiva que se estabelece para a necessidade de o ensino de Língua Portuguesa estar alinhado às práticas sociais de leitura e de escrita. Neste ponto, também por meio de referência cruzada com os documentos e as diretrizes oficiais sobre o ensino de Língua Portuguesa, é possível pontuar a ideia de que, a partir da divisão social do trabalho com a leitura e com a escrita, produziu-se a discursividade de que não é recomendada a didatização de um ensino puramente metalinguístico, por exemplo. Considerou-se que, até pelo perfil de aluno que a escola passou a receber, após a redemocratização do ensino, defender e assegurar um ensino em que o aluno se torne letrado é essencial. Nesse sentido, passou-se a defender a perspectiva de que o ensino metalinguístico não cumpriria a função de possibilitar o letramento. Daí a centralidade na abordagem dos gêneros, como ponto de abordagem do ensino epilinguístico.

Das 11 coleções aprovadas pelo PNLD (2018-2010), escolhemos o livro da coleção "Português Contemporâneo - Diálogo, Reflexão e Uso", de Willian Cereja, Carolina Dias Viana e Cristiane Damien; material divulgado pela editora Saraiva, a coleção de que tratamos é aquela direcionada ao professor. Vejamos, a seguir, um trecho recortado do livro voltado para o primeiro ano do ensino médio regular:

\begin{abstract}
Esta coleção foi escrita para você, que sempre desejou trabalhar com uma obra de língua portuguesa que integrasse os conteúdos de literatura, de gramática e de produção textual. Uma obra que não tratasse os estilos da época da literatura de forma cristalizada e estanque, mas estabelecesse relações dialógicas entre a literatura de um autor e de uma época com obras e autores de outras épocas. Uma obra que apresentasse não apenas os conteúdos essenciais de gramática, mas também uma forma diferente de abordá-los, além de incluir capítulos de discurso com uma perspectiva dos estudos de letramento, com diferentes práticas de leitura e escrita, e que incluísse gêneros da esfera digital e gêneros multimodais, como o roteiro de documentário e o conto multissemiótico (CEREJA, VIANNA, DAMIEN, 2016, p. 341).
\end{abstract}

Nesse recorte, notamos que os autores propõem, nas orientações didáticas aos professores, uma prática pedagógica, em tese, diferente e mais produtiva. Eles sugerem, na introdução das orientações didáticas, que a coleção em foco traz obras direcionadas aos professores, que, sempre, desejaram trabalhar com um livro que integrasse os conteúdos de gramática, de literatura e de redação. É constante, na obra, a discursividade de eles estão propondo uma prática docente que proporcione uma melhor aprendizagem aos alunos. Tais autores destacam, ainda, que esta coleção traz obras para os professores que sempre desejaram uma obra que trabalhasse os gêneros textuais com uma perspectiva dos estudos do letramento, com diferentes práticas de leitura e de escrita e, inclusive, gêneros

Revista do SELL, Uberaba/MG (online) - V. 9 n. 1, p. 142-160, jan. /jun. - 2020. 
SILVA,J.A.R.; LEITE,J.D.

da esfera digital e gêneros multimodais, como o roteiro de documentário e o conto multissemiótico.

Após uma verificação, de página à página, do primeiro livro da coleção em foco, produzimos o Quadro 01 que se segue em que organizamos as seguintes informações: (1) página do livro em que se encontra o gênero textual; (2) gênero textual; (3) instituição a que se refere o gênero; (4) seção do livro em que se está inserido o gênero; (5) eixo do livro didático a que o gênero foi vinculado; (6) conteúdo e/ou atividades que se vinculam ao gênero. Quadro 1:

Quadro 1 - Ocorrência dos gêneros textuais publicitários no livro didático enfocado.

\begin{tabular}{|c|c|c|c|c|c|}
\hline Página & Gênero & Instituição & Seção & $\begin{array}{c}\text { Eixo } \\
\text { Modalidade }\end{array}$ & Conteúdo/Atividades \\
\hline 22 & 1- Anúncio & Amanco & $\begin{array}{l}\text { Foco no } \\
\text { Texto }\end{array}$ & $\begin{array}{c}\text { Língua e } \\
\text { Linguagem }\end{array}$ & $\begin{array}{c}\text { Explicação Língua e } \\
\text { Literatura }\end{array}$ \\
\hline 27 & 2- Anúncio & The Getz & $\begin{array}{l}\text { Texto e } \\
\text { Anúncio }\end{array}$ & $\begin{array}{l}\text { Língua e } \\
\text { Linguagem }\end{array}$ & $\begin{array}{c}\text { Leitura, } \\
\text { Compreensão, } \\
\text { Interpretação }\end{array}$ \\
\hline 30 & 3- Anúncio & Arte e Flor & $\begin{array}{l}\text { Foco no } \\
\text { Texto }\end{array}$ & $\begin{array}{l}\text { Produção } \\
\text { de texto }\end{array}$ & Tipos de Texto \\
\hline 54 & 4- Anúncio & Vintage & $\begin{array}{l}\text { Texto e } \\
\text { Anúncio }\end{array}$ & $\begin{array}{l}\text { Língua e } \\
\text { Linguagem }\end{array}$ & $\begin{array}{c}\text { Exercícios sobre } \\
\text { Variação Linguística }\end{array}$ \\
\hline 55 & 5- Anúncio & Maxmidia & $\begin{array}{l}\text { Texto e } \\
\text { Anuncio }\end{array}$ & $\begin{array}{l}\text { Língua e } \\
\text { Linguagem }\end{array}$ & $\begin{array}{c}\text { Exercícios sobre } \\
\text { Variação Linguística }\end{array}$ \\
\hline 74 & 6- Anúncio & Carta Capital & $\begin{array}{l}\text { Foco no } \\
\text { Texto }\end{array}$ & $\begin{array}{l}\text { Língua e } \\
\text { Linguagem }\end{array}$ & $\begin{array}{l}\text { Explicação sobre } \\
\text { funções da } \\
\text { linguagem }\end{array}$ \\
\hline 77 & 7- Anúncio & Fiat & $\begin{array}{l}\text { Aplique o } \\
\text { que } \\
\text { aprendeu }\end{array}$ & $\begin{array}{c}\text { Língua e } \\
\text { Linguagem }\end{array}$ & $\begin{array}{l}\text { Exercícios sobre } \\
\text { funções da } \\
\text { linguagem }\end{array}$ \\
\hline 78 & 8- Anúncio & $\begin{array}{l}\text { Harley- } \\
\text { Daudson }\end{array}$ & $\begin{array}{l}\text { Texto e } \\
\text { Anúncio }\end{array}$ & $\begin{array}{c}\text { Língua e } \\
\text { Linguagem }\end{array}$ & $\begin{array}{c}\text { Leitura, } \\
\text { Compreensão, } \\
\text { Interpretação }\end{array}$ \\
\hline 90 & 9- Cartaz & $\begin{array}{l}\text { Ministério da } \\
\text { Saúde }\end{array}$ & $\begin{array}{l}\text { Enem em } \\
\text { Contexto }\end{array}$ & $\begin{array}{l}\text { Língua e } \\
\text { Linguagem }\end{array}$ & $\begin{array}{c}\text { Leitura, } \\
\text { Compreensão, } \\
\text { Interpretação }\end{array}$ \\
\hline 108 & 10-Anúncio & Inac & $\begin{array}{l}\text { Reflexão } \\
\text { sobre } \\
\text { Língua }\end{array}$ & $\begin{array}{c}\text { Língua e } \\
\text { Linguagem }\end{array}$ & $\begin{array}{l}\text { Explicação sobre } \\
\text { figuras de } \\
\text { linguagem }\end{array}$ \\
\hline 115 & 11-Anúncio & $\begin{array}{l}\text { Bienal do } \\
\text { Livro }\end{array}$ & $\begin{array}{l}\text { Aplique o } \\
\text { que } \\
\text { aprendeu }\end{array}$ & $\begin{array}{l}\text { Língua e } \\
\text { Linguagem }\end{array}$ & $\begin{array}{l}\text { Exercícios de } \\
\text { figuras de } \\
\text { linguagem }\end{array}$ \\
\hline 116 & 12-Anúncio & Destak & $\begin{array}{l}\text { Texto e } \\
\text { Anúncio }\end{array}$ & $\begin{array}{l}\text { Língua e } \\
\text { Linguagem }\end{array}$ & $\begin{array}{c}\text { Exercícios, } \\
\text { Compreensão, } \\
\text { Interpretação }\end{array}$ \\
\hline 136 & 13-Anúncio & Fazauto & $\begin{array}{l}\text { Reflexão } \\
\text { sobre } \\
\text { Língua }\end{array}$ & $\begin{array}{c}\text { Língua e } \\
\text { Linguagem }\end{array}$ & $\begin{array}{c}\text { Explicação sobre } \\
\text { Polissemia }\end{array}$ \\
\hline
\end{tabular}

Revista do SELL, Uberaba/MG (online) - V. 9 n. 1, p. 142-160, jan. /jun. - 2020. 
SILVA,J.A.R.; LEITE,J.D.

\begin{tabular}{|c|c|c|c|c|c|}
\hline 137 & 14-Anúncio & Rolling Stone & $\begin{array}{l}\text { Aplique o } \\
\text { que } \\
\text { aprendeu }\end{array}$ & $\begin{array}{c}\text { Língua e } \\
\text { Linguagem }\end{array}$ & $\begin{array}{l}\text { Exercícios sobre } \\
\text { semântica }\end{array}$ \\
\hline 140 & 15-Anúncio & O Estadão & $\begin{array}{l}\text { Texto e } \\
\text { Anúncio }\end{array}$ & $\begin{array}{l}\text { Língua e } \\
\text { Linguagem }\end{array}$ & $\begin{array}{c}\text { Leitura, } \\
\text { Compreensão e } \\
\text { Interpretação }\end{array}$ \\
\hline 140 & 16-Anúncio & Insetsan & $\begin{array}{l}\text { Texto e } \\
\text { Anúncio }\end{array}$ & $\begin{array}{c}\text { Língua e } \\
\text { Linguagem }\end{array}$ & $\begin{array}{l}\text { Explicação sobre } \\
\text { implicação Indireta }\end{array}$ \\
\hline 153 & 17-Anúncio & Unimed & $\begin{array}{l}\text { Foco no } \\
\text { Texto }\end{array}$ & $\begin{array}{c}\text { Língua e } \\
\text { Linguagem }\end{array}$ & $\begin{array}{l}\text { Explicação sobre } \\
\text { implicação Indireta }\end{array}$ \\
\hline 154 & 18-Anúncio & Imibiliária & $\begin{array}{l}\text { Foco no } \\
\text { Texto }\end{array}$ & $\begin{array}{l}\text { Língua e } \\
\text { Linguagem }\end{array}$ & $\begin{array}{l}\text { Exercícios sobre } \\
\text { semântica }\end{array}$ \\
\hline 156 & 19-Anúncio & Havaianas & $\begin{array}{l}\text { Aplique o } \\
\text { que } \\
\text { aprendeu }\end{array}$ & $\begin{array}{c}\text { Língua e } \\
\text { Linguagem }\end{array}$ & $\begin{array}{l}\text { Explicação sobre } \\
\text { sons e letras }\end{array}$ \\
\hline 187 & 20-Anúncio & $\begin{array}{c}\text { Hospital } \\
\text { Dona Helena }\end{array}$ & $\begin{array}{l}\text { Reflexão } \\
\text { sobre } \\
\text { Língua }\end{array}$ & $\begin{array}{c}\text { Língua e } \\
\text { Linguagem }\end{array}$ & $\begin{array}{c}\text { Leitura, } \\
\text { compreensão, } \\
\text { interpretação }\end{array}$ \\
\hline 239 & 21-Anúncio & $\begin{array}{c}\text { Super } \\
\text { Esportes }\end{array}$ & $\begin{array}{l}\text { Texto e } \\
\text { Anúncio }\end{array}$ & $\begin{array}{c}\text { Língua e } \\
\text { Linguagem }\end{array}$ & $\begin{array}{l}\text { Explicação coerência } \\
\text { coesão }\end{array}$ \\
\hline 266 & 22-Anúncio & Citibank & $\begin{array}{l}\text { Foco no } \\
\text { Texto }\end{array}$ & $\begin{array}{l}\text { Língua e } \\
\text { Linguagem }\end{array}$ & $\begin{array}{l}\text { Exercícios coerência } \\
\text { e coesão }\end{array}$ \\
\hline 271 & 23-Anúncio & Diário Bahia & $\begin{array}{l}\text { Aplique o } \\
\text { que } \\
\text { aprendeu }\end{array}$ & $\begin{array}{l}\text { Língua e } \\
\text { Linguagem }\end{array}$ & $\begin{array}{c}\text { Exercícios sobre } \\
\text { formação das } \\
\text { palavras }\end{array}$ \\
\hline 312 & 24-Anúncio & Honda & $\begin{array}{l}\text { Aplique o } \\
\text { que } \\
\text { aprendeu }\end{array}$ & $\begin{array}{c}\text { Língua e } \\
\text { Linguagem }\end{array}$ & $\begin{array}{c}\text { Exercícios sobre } \\
\text { formação das } \\
\text { Palavras }\end{array}$ \\
\hline 314 & 25-Anúncio & Pliladelphia & $\begin{array}{l}\text { Aplique o } \\
\text { que } \\
\text { aprendeu }\end{array}$ & $\begin{array}{c}\text { Língua e } \\
\text { Linguagem }\end{array}$ & $\begin{array}{c}\text { Leitura, } \\
\text { compreensão e } \\
\text { interpretação }\end{array}$ \\
\hline 316 & 26-Anúncio & Mazuna & $\begin{array}{l}\text { Texto e } \\
\text { Anúncio }\end{array}$ & $\begin{array}{c}\text { Língua e } \\
\text { Linguagem }\end{array}$ & $\begin{array}{c}\text { Leitura, } \\
\text { compreensão e } \\
\text { interpretação }\end{array}$ \\
\hline
\end{tabular}

Fonte: Elaboração dos autores.

De posse desse quadro, notamos a predominância do gênero "anúncio publicitário", do meio daqueles da esfera publicitária, isto é, de uma esfera socialmente constituída, para fazermos menção ao Edital e ao Guia, anteriormente aludidos. E esses anúncios estão em função de se vender um produto em si. Talvez, se fossem anúncios publicitários que vendessem uma ideia em si, no campo de valores sociais, haveria um certo risco, dadas as questões ideológicas autorizadas e desautorizadas no e pelo livro didático. Os anúncios que ocorrem estão em função, predominantemente, no eixo "língua e linguagem"; em geral, na seção "Foco no texto". Por ser um gênero em que a linguagem verbal e não verbal se articulam, é explicável que ele apareça na seção em que questões de linguagem sejam tematizadas. No que diz respeito à abordagem dos conteúdos, no processo de divisão 
SILVA,J.A.R.; LEITE,J.D.

social do trabalho de leitura e de escrita, esse gênero serve de base para o trabalho didático com diferentes aspectos da Língua Portuguesa.

\section{Processos discursivos da abordagem do gênero anúncio publicitário}

Neste artigo, analisamos a ocorrência de um anúncio publicitário e os exercícios a ele relacionados em específico, dada a nossa inscrição na Análise de Discurso francesa. Estamos interessados nos processos materiais que constituem o gesto de apropriação do anúncio publicitário no livro didático de Língua Portuguesa. Sob a perspectiva discursiva, cabe destacar que está na base desse gesto de apropriação o plano da formulação. É que, no lugar discursivo de autor(es), esse plano ancora operações de seleção e de exploração do gênero textual em questão, implicando uma tomada de posição diante dessas operações. A análise empreendida por nós, neste artigo, é produzida a partir de um recorte de um anúncio, como já destacamos, contudo esse recorte mostra uma certa recorrência de abordagem existente, no âmbito do livro didático em tela.

O procedimento de análise elaborado por nós se orienta pelos seguintes aspectos, que nos permitiram conceber o plano da formulação: (1) identificação da esfera social em que o anúncio publicitário circulou originalmente; (2) identificação da natureza do anúncio publicitário, mostrando a sua estruturação, em termos de linguagem verbal e não verbal; (3) identificação e análise de outras materialidades que coocorrem com o anúncio publicitário; identificação e análise do eixo do ensino de Língua Portuguesa, no ensino médio, e da seção em que eles ocorrem, não perdendo de vista a articulação com outras materialidades significantes; (4) análise e problematização do modo como essa ocorrência entre anúncio publicitário e outras materialidades significantes colaboram ou não para a "divisão social do trabalho da leitura" e da escrita. O nosso interesse maior refere-se aos pontos de dispersão que acabam por deflagrar que essa formulação traz em seu bojo de constituição elementos de contradição.

Vejamos o primeiro recorte discursivo de análise, a partir do qual apresentamos o anúncio publicitário:

RD1

Revista do SELL, Uberaba/MG (online) - V. 9 n. 1, p. 142-160, jan. /jun. - 2020. 
Figura 1 - Anúncio publicitário presente na seção "Foco no texto", no eixo "Língua e linguagem" do livro didático enfocado.

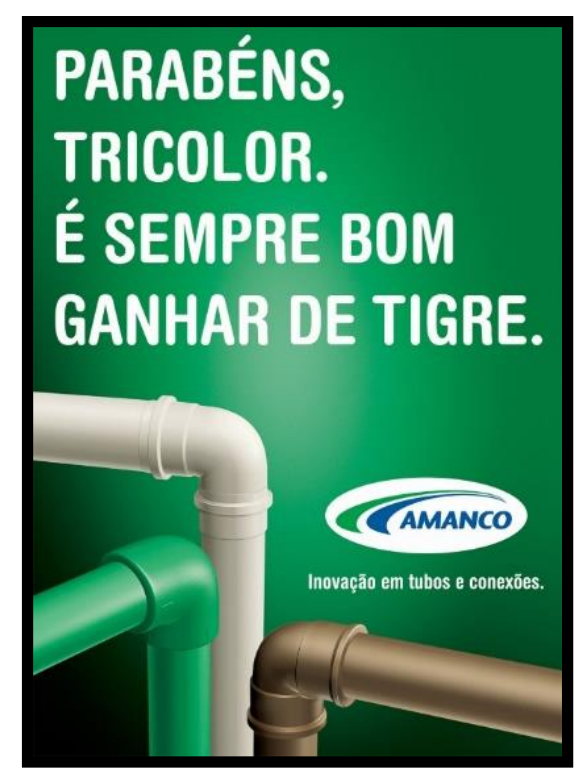

Fonte: Recorte do livro didático "Português contemporâneo - Diálogo; reflexão e uso" (CEREJA, VIANNA e DAMIEN, 2016, p. 22).

O anúncio é composto pelo enunciado "Parabéns, tricolor. É sempre bom ganhar com Tigre", além da logomarca da empresa "Amanco", bem como pelo enunciado "Inovação em tubos e conexões". Além desses enunciados, o anúncio publicitário é composto, também, pelo texto não verbal imagético representado por imagens de canos e conexões de PVC. Não perdendo de vista as condições materiais dos sentidos, em que aspectos da trajetória de filiação se constitui e outros se apagam, perguntamo-nos: Em que espaços sociais esse anúncio circulou? Quando? E com que finalidade? Quando esse anúncio publicitário circula em outros espaços sociais, ele tem a função de vender um produto. No espaço escolar, mais precisamente no âmbito do livro de didático, essa função desloca-se para qual função? Ou de quê? Para quê?

Por meio do recurso do Google, fizemos uma busca por informações sobre o referido anúncio publicitário. Ao fazermos referência cruzada com os diferentes sites acessados, percebemos que esse anúncio foi publicado em jornais, em revistas e na internet em dezembro de 2012. Ele circulou logo após a vitória do time São Paulo Futebol Clube, na copa Sul-Americana, sobre o time Club Atlético Tigre; trata-se de um time de futebol argentino. Cabe salientar que o time São Paulo é conhecido, também, por Tricolor. 
SILVA,J.A.R.; LEITE,J.D.

Contudo, salientamos, também, que outros times podem ser considerados tricolores, como o Fluminense, o Bahia, ou outro time com esses títulos naquele período.

Neste ponto, podemos pensar que o gesto de apropriação desse anúncio publicitário deixa entrever certa "potencialidade didática", pois ele é composto de linguagem verbal e não verbal. Desse modo, trata-se de uma gênero textual que, em tese, poderá criar condições para a abordagem de elementos do texto, ou particularizando questões sobre o verbal e sobre o não verbal, ou mesmo a relação entre eles, ou ainda um apagamento da abordagem do texto não verbal imagético (Cf. AGUSTINI, ARAUJO, LEITE, 2017), como é muito comum no gesto de didatização dos gêneros constituídos pela linguagem verbal e não verbal. Como essa "potencialidade didática" é formulada no livro didático em questão?

Já pensando no gesto de apropriação produzido pelos autores do livro didático em questão, neste artigo, consideremos, a seguir, o próximo recorte discursivo:

RD2

Figura 2 - Exercícios de leitura-interpretação do gênero anúncio publicitário e parte da atividade da seção "Foco no texto".

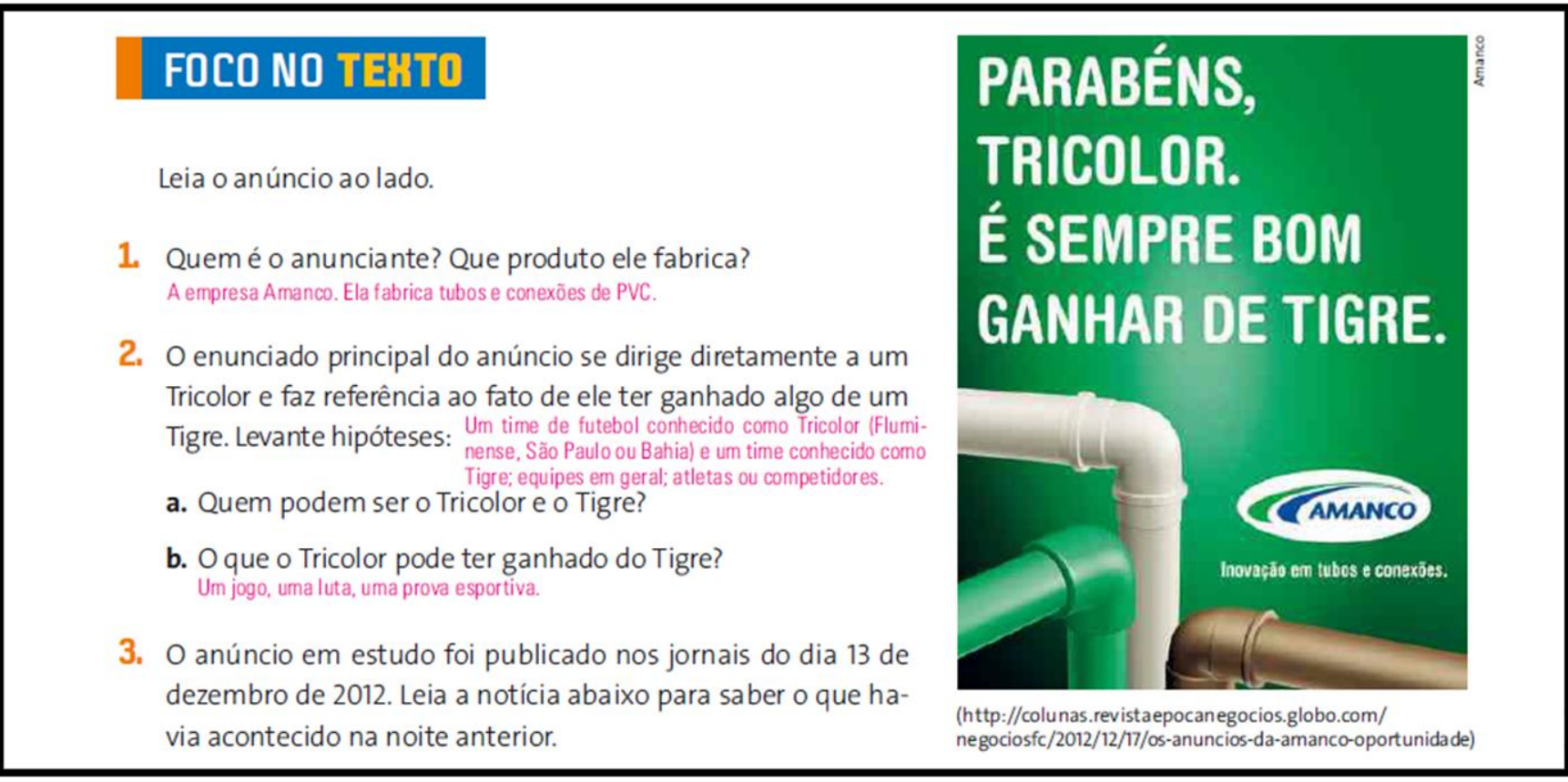

Fonte: Recorte do livro didático "Português contemporâneo - Diálogo; reflexão e uso" (CEREJA, VIANNA e DAMIEN, 2016, p. 22).

Concebendo o plano da formulação, e não perdendo de vista os efeitos da didatização do gênero anúncio publicitário, notamos que outras materialidades significantes coocorrem com ele: comentários, exercícios e outros gêneros textuais, como deixa entrever a questão 03 desta lista de exercício. Ao ser apropriado, na esfera escolar, como deixa flagrar o livro didático, a função social dele se desloca para quê? E de que modo? Neste

Revista do SELL, Uberaba/MG (online) - V. 9 n. 1, p. 142-160, jan. /jun. - 2020. 
SILVA,J.A.R.; LEITE,J.D.

ponto, estamos considerando os processos discursivos que estão na base dos deslocamentos dos textos e dos sentidos que a partir dele são formulados, tendo como horizonte a esfera que ancora a circulação.

No processo de apropriação, até por ser um livro didático que está subdividido em unidades, em capítulos, em seções e em subseções, a ocorrência da formulação "Foco no texto" produz alguns efeitos de sentido. Por que foco no texto e, não, na gramática, por exemplo? De que natureza será esse foco? Será explorado a linguagem verbal e a linguagem não verbal? Quais elementos da esfera em que esse anúncio circulou, primeiramente, será abordado? Em termos de "potencialidade didática", de que modo esses elementos ganham uma didatização?

A formulação "Leia o anúncio ao lado.", no gesto de apropriação produzido pelos autores, introduz a identificação de que o texto a ser lido é um "anúncio". Essa formulação, em termos de processos discursivos, passa a direcionar sentidos, pois a leiturainterpretação do texto já passa a ser afetada pelo sentido de que se trata de um "anúncio". Cabe ressaltar que essa formulação figura como outra materialidade significante, que é "comentário", que o processo discursivo da didatização faz constituir neste ponto de abordagem do livro. A formulação "publicitário" é apagada no livro didático, trabalhando-se que a nomeação genérica de anúncio. Esse apagamento estaria em função de que especificar "publicitário" compromete o caráter gradual de construção de sentido sobre o anúncio em tela? Ou essa especificação não faria diferença no processo de leiturainterpretação?

Articulado ao anúncio publicitário, coocorrem também a materialidade significante "exercícios". Nesse recorte discursivo, aparecem três perguntas, sendo que a pergunta de número 2 subdivide-se em letras "a" e "b". A formulação da pergunta 1 introduz elementos, como "anunciante" e "produto que ele fabrica", que acabam produzindo efeitos na didatização do anúncio publicitário em tela. Essa formulação põe em operação uma perspectiva de que ler é localizar informações, já que leva o aluno a identificar quem é o anunciante e que produto ele fabrica. Identifica-se, a partir do verbal e do não verbal, sem levar um trabalho mais consistente com a linguagem, ainda que o eixo de ensino de Língua Portuguesa seja "língua e linguagem".

A formulação da pergunta 2 já busca levar o aluno a construir sentidos com base no anúncio. No enunciado introdutório da pergunta, são tematizadas discursividades constantes da própria formulação principal do anúncio. Formula-se que há um "enunciado principal", e que este está dirigido a um Tricolor, tendo em vista o vocativo "Tricolor" que ocorre na formulação. Além disso, formula-se que Tricolor ganhou algo de um Tigre. A 
SILVA,J.A.R.; LEITE,J.D.

poder dessa formulação, as alternativas "a" e "b" busca criar condições, para que o aluno formule as hipóteses de quem é o "Tricolor", o "Tigre" e o "prêmio" ganhado. Já se trata de uma formulação que busca levar o aluno a relacionar os sentidos, mas tendo como foco a predominância da apropriação da linguagem verbal, a depender do aluno que lê.

Do ponto de vista da "potencialidade didática" do anúncio em tela, o trabalho didático com o não verbal vai sendo apagado, já que, na trajetória de filiação de sentido, não se tematiza o não verbal. Eis um ponto em que a "divisão social do trabalho da leitura" e da escrita ganha uma evidência, pois a exploração didática se circunscreve à linguagem verbal. Por exemplo, a formulação de hipóteses, da parte do aluno, pode levar em conta ou não o não verbal, em articulação com a formulação "Inovação em tubos e conexões". Tratase uma trajetória muito em função do aluno e menos das condições criadas pelo processo de didatização do texto em questão.

A formulação da pergunta 3 introduz novas informações no processo de didatização do anúncio, sendo explicitado o espaço discursivo e a data de circulação do referido texto. Nesse processo de didatização outro gênero é mobilizado, qual seja: uma notícia, buscando-se criar condições para a leitura e a escrita a partir do anúncio. No próprio enunciado da formulação já aparece a nomeação de que se trata de uma notícia. A notícia é intitulada do seguinte modo: "Após confusão, Tigre abandona o campo e São Paulo é campeão da Sul-Americana". A formulação da pergunta 3, que aparece depois da notícia, demanda que o aluno responda se, após a leitura-interpretação da notícia, houve a confirmação ou a negação das hipóteses levantadas por ele. Uma vez mais, a discursividade de leitura como localização e como constatação de informações no texto ou a partir dele aparece em funcionamento. Em termos de "potencialidade didática", não se discursiviza a leitura fundamentada do aluno para além de constituintes dos textos. No processo de divisão social do trabalho com a leitura e com a escrita, produz-se um apagamento das condições de produção do texto, de modo a não levar o aluno a tematizar seu percurso de leitura e de escrita.

Consideremos, a seguir, o próximo recorte discurso do trabalho de análise:

RD3 
Figura 3 - Exercícios de leitura-interpretação de parte da atividade da seção "Foco no texto".

Após confusão, Tigre abandona o campo e São Paulo é campeão da Sul-Americana

FEUPE ROSA MENDES - AGENCLAESTADO 12 Desem bro 201221 hoo

Depois de mais de 30 minutos de confusāo, indefiniçāo e conversas entre dirigentes, o árbitro chileno apitou ofinal do jogo

SÃo PAULO - O São Paulo conquistou nesta quarta-feira o titulo da Copa Sul-Americana de forma inesperada. No intervalo da partida no estádio do Morumbi, com o time brasileiro vencendo por 2 a 0 - com gols de Lucas e Osvaldo -, o time argentino do Tigre nāo voltou ao campo. Depois de mais de 30 minutos de muita confusāo, indefinição e conversas entre dirigentes, o àrbitro chileno Enrique Osses apitou ofinal do jogomesmo sem a presença dos argentinos.

Apesar do anticlimax, os jogadores sāo-paulinos, no gramado, puderam então comemorar a inèdita conquista da competiçâo continental, acompanhados de 67 mil torcedores presentes no Morumbi, encerrando um jejum de quatro anos sem trofèus. OSāo Paulonāo faturava um titulo desde a conquista do Campeonato Brasileiro de 2008.

Responda: O relato feito na noticia confirma ou nega as hipóteses levan-

tadas na questão anterior? Resposta pessoal.

4. Faça uma pesquisa ou consulte os colegas e o professor sobre os nomes

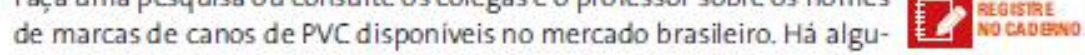

ma que pode ser associada a algum dos termos do anúncio?

Espea-se que os alunos, se náo corhecent encontem facimente en uma pesquisa rápida que Tige e

onome de uma macca reccoherida no merado

Fonte: Recorte do livro didático "Português contemporâneo - Diálogo; reflexão e uso" (CEREJA, VIANNA e DAMIEN, 2016, p. 22).

A formulação da pergunta 4 tematiza, por meio de um enunciado introdutório, a necessidade de o aluno proceder a uma pesquisa, ou mesmo uma consulta aos colegas ou ao professor, buscando produzir um levantamento de marcas de canos de PVC que atendem o mercado brasileiro. Após esse procedimento, demanda-se que o aluno identifique se, das marcas existentes, há alguma que tem relação com o anúncio. Uma vez mais, no processo de didatização do anúncio em questão, a discursividade de leitura como localização e como constatação de informações no texto ou a partir dele aparece em evidência.

Conforme viemos considerando, neste artigo, os processos discursivos que ancoram o gesto de apropriação do anúncio publicitário, nesse livro didático, produzem: (1) efeito de unidade diante da concepção de leitura e de escrita, como localização e como constatação de informações do texto lido/interpretado; (2) efeito de dispersão frente à concepção de leitura fundamentada que relacione o texto com as suas condições de produção e de circulação na sociedade. A didatização em jogo, portanto, não rompe com a "divisão social 
SILVA,J.A.R.; LEITE,J.D.

do trabalho da leitura" e da escrita vigentes no espaço escolar. Há um modus operandi: seleciona-se o texto, formula-o no âmbito do livro didático para se trabalhar ou a estruturação do gênero, priorizando os seus constituintes.

\section{CONSIDERAÇÕES FINAIS}

Inscritos em teorizações de Pêcheux (2014), partimos da perspectiva de que a formulação, em sua relação com certas discursividades de leitura e de escrita, significa o gesto de apropriação desse gênero textual, no livro, em função do jogo entre unidade e dispersão de sentidos. Como analisamos, articulado ao anúncio publicitário, aparecem outras materialidades significantes, tais como: comentários, exercícios produzidos para a abordagem didática do texto, ilustrações, outros gêneros textuais. As análises mostraram, no caso específico, que a construção de redes de implícitos, no trabalho de leitura e de escrita do anúncio, dependem justamente de outros elementos exteriores à materialidade desse gênero textual. Para este artigo, enfocamos um livro didático da coleção "Português Contemporâneo - diálogo, reflexão e uso", de Cereja, Dias Vianna e Damien (PNLD 20182020), especificamente o volume direcionado ao professor, como ressaltamos anteriormente, analisando o gênero textual em foco, de maneira a destacar algumas discursividades produzidas pelo fato de os autores da referida coleção deslocarem o anúncio publicitário para o livro didático de português.

Para tanto, mobilizamos um anúncio publicitário da seção "Foco no Texto", dado o eixo "Língua e Linguagem", conforme configuração do livro em questão. Nesse sentido, tematizamos a perspectiva de que, quando o livro ganhou circulação, pois se trata do PNLD 2018-2020, o aluno é levado a formular sua trajetória de leitura e de escrita a partir da discursividade de que se trata de atividades meramente como localização e constatação de informações do texto lido/interpretado.

Por fim, cabe ressaltar que o livro didático (LD) ocupa um lugar de destaque, no espaço escolar brasileiro, haja vista o funcionamento do PNLD. Em torno desse Programa, há uma construção discursiva de que as obras didáticas, pedagógicas e literárias, a serem adotadas em escolas públicas brasileiras, precisam ser fruto de um processo de avaliação e de seleção consistentes. Sobretudo, elas precisam estar alinhadas às discursividades sobre o ensino e a aprendizagem no espaço escolar brasileiro. Há a institucionalização de sentidos por meio de objetos simbólicos (Diretrizes Curriculares, Documentos oficiais, Edital de Convocação do PNLD, Guia de livros didáticos do PNLD, dentre outros), que passam a orientar as práticas sociais dos profissionais da escola, ou daqueles concernidos por ela. 
SILVA,J.A.R.; LEITE,J.D.

Na esteira de Pêcheux (1994), esses objetos simbólicos integram um arquivo sobre o ensino e a aprendizagem em nosso país.

\section{REFERÊNCIAS}

AGUSTINI, Cármen Lúcia Hernandes; ARAÚJO, Érica Daniela de, LEITE, João de Deus. A leitura do texto não-verbal imagético em livros didáticos: reflexões a partir de um olhar discursivo. Entremeios [Revista de Estudos do Discurso, on-line], Seção Temática Língua(gem) e Ensino, Programa de Pós-Graduação em Ciências da Linguagem (PPGCL), Universidade do Vale do Sapucaí (UNIVÁS), Pouso Alegre (MG), vol. 14, p. 213-231, jan. jun. 2017.

PÊCHEUX, Michael. Ler o arquivo hoje. In: ORLANDI, Eni P. (org.). Gestos de leitura: da história no discurso. 4. ed. Campinas: Editora da Unicamp, 2014. cap. III, ISBN 978-85268-1054-9.

ORLANDI, Eni Puccinelli. Análise de Discurso: princípios \& procedimentos. 8. ed. Campinas: Pontes, 2014. P.100.

MINISTÉRIO DA EDUCAÇÃO (Brasil). Governo Federal. Edital da convocação no 04/2015. Edital de convocação para processo de inscrição e avaliação de obras didáticas para o Programa Nacional do Livro Didático PNLD 2019, Brasília, ano 2015, n. 04, 2015.

BRASIL. Ministério da Educação. PNLD 2018: Língua portuguesa - guia de livros didáticos

- Ensino Médio/ Ministério da Educação - Secretaria de Educação Básica - SEB - Fundo Nacional de Desenvolvimento da Educação. Brasília, DF: Ministério da Educação, Secretaria de Educação Básica, 2017. 109 p.

CEREJA, Willian Roberto; VIANNA, Carolina Assis Dias; CODENHOTO, Christiane Damien. Português Contemporâneo: diálogo, reflexão e uso. 1. ed. São Paulo: Saraiva, 2016. v. 1.

\section{Como citar este artigo (ABNT)}

SILVA,J.A.R.; LEITE,J.D. Didatização do gênero anúncio publicitário no livro didático de português do ensino médio: uma abordagem discursiva. SELL, Uberaba, MG, v. X, n. X, p. XXX-XXX, 2019. Disponível em: <inserir link de acesso>. Acesso em: inserir dia, mês e ano de acesso. DOI: inserir link do DOI.

Como citar este artigo (APA)

Silva,J.A.R. \& Leite,J.D. Didatização do gênero anúncio publicitário no livro didático de português do ensino médio: uma abordagem discursiva. SELL, $X(X), X X X-X X X$. Recuperado em: inserir dia, mês e ano de acesso de inserir link de acesso. DOI: inserir link do DOI. 